\title{
Electron rich triarylphosphines as nucleophilic catalysts for oxa- Michael reactions
}

\author{
Susanne M. Fischer, ${ }^{\mathrm{a}, \mathrm{b}}$ Simon Renner, ${ }^{\mathrm{a}}$ A. Daniel Boese,${ }^{\mathrm{c}}$ Christian Slugovc ${ }^{\mathrm{a}, \mathrm{b}, *}$
}

a Institute for Chemistry and Technology of Materials, Graz University of Technology, Stremayrgasse 9, 8010 Graz, Austria; email: slugovc@tugraz.at

${ }^{\mathrm{b}}$ Christian Doppler Laboratory for Organocatalysis in Polymerization, Stremayrgasse 9, 8010 Graz, Austria

c Physical and Theoretical Chemistry, Institute of Chemistry, University of Graz, Heinrichstrasse 28/IV, 8010 Graz, Austria

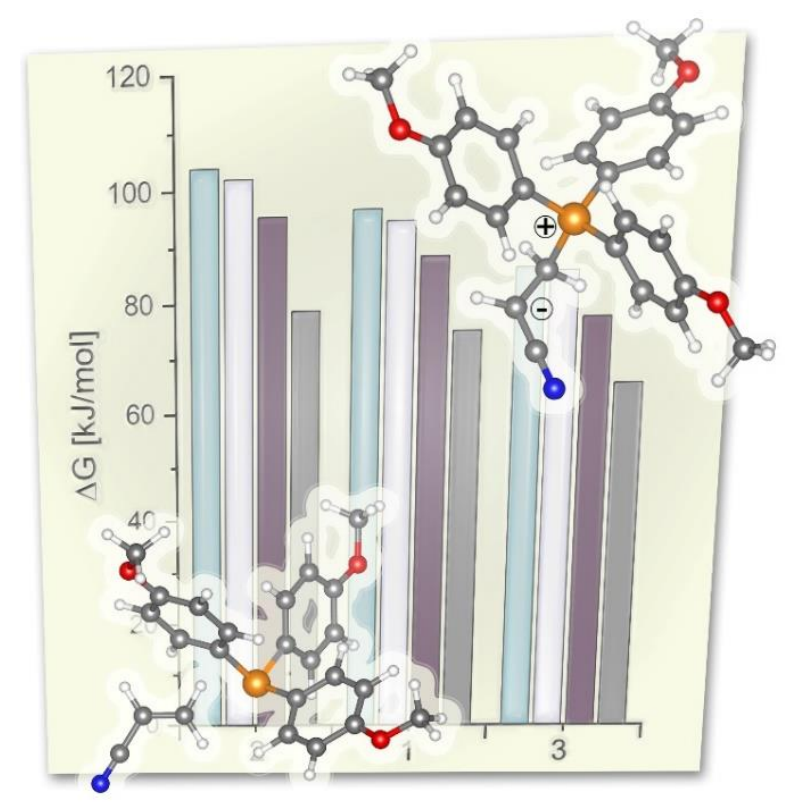

\begin{abstract}
Herein, we study the activity of methoxysubstituted arylphosphines (4-methoxyphenyl)diphenylphosphine (MMTPP) and tris(4-trimethoxyphenyl)phosphine (TMTPP) in catalyzing oxa-Michael additions in comparison to commonly used triphenylphosphine (TPP). Acrylonitrile, acryl amide and divinyl sulfone are used as Michael acceptors and propargyl alcohol, allyl alcohol, $n$-propanol and $i$-propanol are assessed as Michael donors. In many cases, catalyst loadings of only $1 \mathrm{~mol} \%$ in respect to the Michael acceptor are sufficient to provide full conversion towards the Michael adduct in $24 \mathrm{~h}$ at room temperature. Generally, TMTPP is the most active catalyst in all cases. The experimental activity trend was rationalized by calculating the Michael acceptor affinities of all phosphine - Michael acceptor combinations. Besides this parameter, the acidity of the alcohol has a strong impact on the reaction speed. The oxidation stability of the phosphines was evaluated and electron richest TMTPP was found to be only slightly more sensitive to oxidation than TPP. Finally, the catalysts were employed in the oxa-Michael polymerization of 2-hydroxyethyl acrylate. With TMTPP polymers characterized by number average molar masses of about $1200 \mathrm{~g} / \mathrm{mol}$ at room temperature are accessible. Polymerizations carried out at $80{ }^{\circ} \mathrm{C}$ resulted in macromolecules containing a considerable share of Rauhut-Currier type repeat units and consequently lower molar masses were obtained.
\end{abstract}




\section{Introduction}

Phosphines are potent nucleophiles that are used as catalysts in many reactions, like RauhutCurrier, Morita-Baylis-Hillman or Michael reactions. ${ }^{1,2}$ The first step of these reactions is a conjugate addition of the phosphine to an activated electrophile, e.g. an electron-deficient olefin, generating a zwitterion (i, Scheme 1). In further course, the zwitterion acts as a nucleophile or as a base. ${ }^{1}$ The efficiency of the formation of this $\beta$-phosphonium $\alpha$-carbanionic species depends on the nucleophilicity of the phosphine which is usually stronger in trialkylphosphines and decreases with aryl substitution. ${ }^{3,4}$ Consequently, the first phosphinecatalyzed reactions have been described with trialkylphosphines. ${ }^{5,6,7,8}$ However, trialkylphosphines are characterized by a pronounced oxidation sensitivity demanding the exclusion of oxygen. This issue can be mitigated by using triarylphosphines that are by far less prone to oxidation. Both, the rate of oxidation and the reactivity in nucleophilic additions correlate with the electron density residing on the phosphorous center. ${ }^{9,10,11}$ Accordingly, triarylphosphines are generally less reactive in conjugate additions than trialkylphosphines and often high catalyst loadings of up to $20 \mathrm{~mol} \%$ and elevated temperatures are necessary to obtain satisfactory conversions. ${ }^{4,12,13}$ The low reactivity of arylphosphines can be enhanced by introducing electron donating groups (e.g. $-\mathrm{CH}_{3},-\mathrm{OMe},-\mathrm{NMe}_{2}$ ) at the aryl moieties. In this way, the electron density on phosphorous and thus nucleophilicity is increased. This strategy has for example been exploited in the reaction of ethyl acrylate with 4-nitrobenzaldehyde, ${ }^{14}$ in aza Morita-Baylis Hilman reactions, ${ }^{15}$ or in umpolung [3+2] annulations. ${ }^{16}$ In all these cases, the reactions were performed without protective gas indicating that electronically modified arylphosphines tolerate the presence of oxygen.

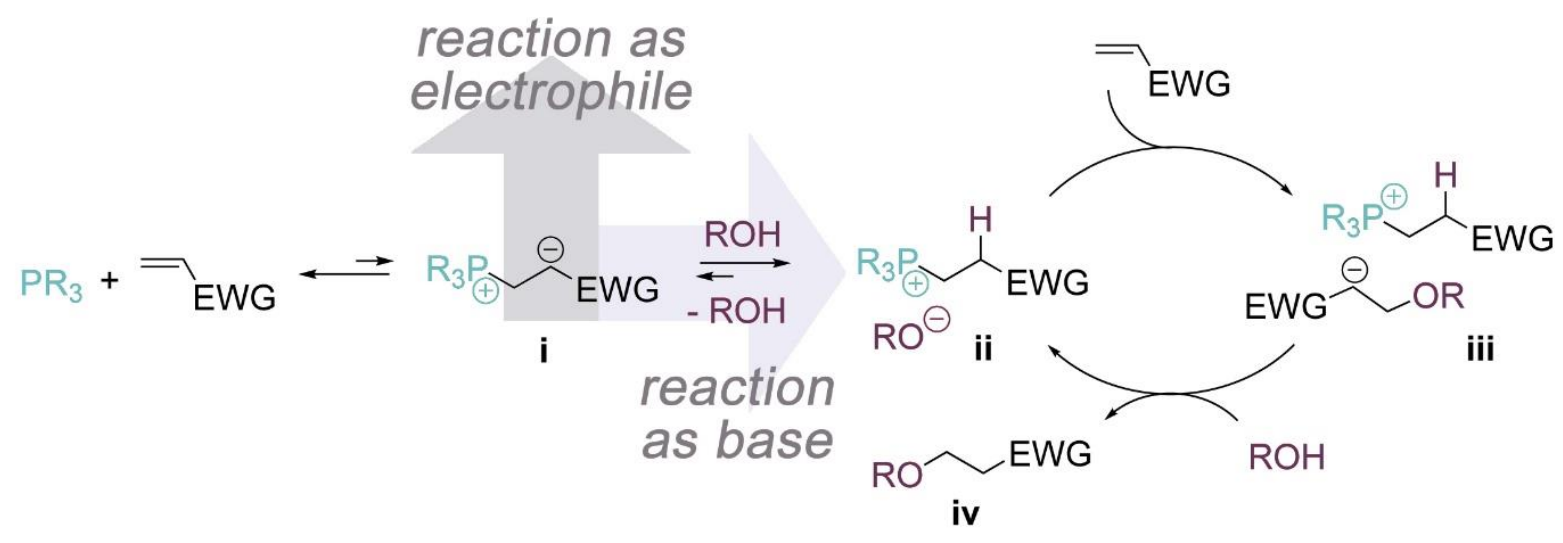

Scheme 1. Mechanism for the phosphine-initiated oxa-Michael addition

Herein we wish to report the scope of three different triarylphosphine catalysts in the oxaMichael addition. Triphenylphosphine (TPP), (4-methoxyphenyl)diphenylphosphine (MMTPP) and tris(4-trimethoxyphenyl)phosphine (TMTPP) are investigated as catalysts in the reaction of four different Michael acceptors with four different alcohols. In the oxa-Michael addition, the zwitterion $\mathbf{i}$ is believed to be protonated by the alcohol forming ion pair ii, consisting of a phosphonium cation and an alkoxide. The alkoxide in ii then reacts with another electrophile generating ion pair iii. In the final step, the $\alpha$-carbanionic species in iii gets protonated by an alcohol generating the $o x a$-Michael addition product (iv) and regenerating ii (Scheme 1). Our results contribute to the rational selection of proper catalysts for this and similar reactions also considering the oxygen sensitivity of the nucleophiles. 


\section{Results and Discussion}

To compare the activity of the triarylphosphines TPP, MMTPP and TMTPP as catalysts for the oxa-Michael reaction three varyingly strong Michael acceptors, namely acrylonitrile (1), acrylamide (2) and divinyl sulfone (3) were reacted with four different alcohols of similar molecular mass but different acidity (Figure 1). The stoichiometry of Michael acceptor to alcohol was set to 1 to 2 and no solvent was used. The reaction was carried out at room temperature with $1 \mathrm{~mol} \%$ catalyst (in respect to the Michael acceptor). The reaction progress was monitored after $1 \mathrm{~h}$ and $24 \mathrm{~h}$ using ${ }^{1} \mathrm{H}$-NMR spectroscopy. The set-up of the study aims to show the scope and the limitations of the different catalysts. An optimization of the reaction conditions in terms of obtaining full conversion in the shortest time possible with the lowest reasonable achievable catalyst loading was not undertaken. Results are shown in Fig. 1. The benchmark catalyst TPP is unable to promote the oxa-Michael reaction of the good Michael acceptor 1 (electrophilicity parameter $\mathrm{E}$ of -19.05$)^{17}$ with the least acidic alcohol 2-propanol a as virtually no conversion was observed after $24 \mathrm{~h}$. Using MMTPP leads to a minor improvement and $3 \%$ conversion towards 1a was found after $24 \mathrm{~h}$. TMTPP, however, gives already $4 \%$ conversion after $1 \mathrm{~h}$ and $38 \%$ conversion after $24 \mathrm{~h}$. More acidic 1-propanol b reacts in the presence of TPP (27\% conversion after $24 \mathrm{~h}$ ). MMTPP already provides a considerable improvement since a conversion of $66 \%$ is obtained after $24 \mathrm{~h}$ but TMTPP is again a distinctly better catalyst providing $73 \%$ conversion after $1 \mathrm{~h}$ and almost full conversion (98 $\%$ ) after $24 \mathrm{~h}$. Allyl alcohol $\mathbf{c}$ is more reactive than 1-propanol as conversions with all catalysts at all conditions are slightly higher. Most importantly, the TMTPP catalyzed reaction shows already $86 \%$ conversion after $1 \mathrm{~h}$. In sharp contrast, propargyl alcohol $\mathbf{d}$, the most acidic one, gave only about $24 \%$ conversion after $1 \mathrm{~h}$ irrespective of which catalyst had been used. After $24 \mathrm{~h}$ almost full conversion (97\% TPP or $99 \%$ MMTPP and TMTPP) was found for all three catalysts. Accordingly, in this case, the activity of the catalyst is not rate determining. This observation is rationalized by the occurrence of a non-productive acid-base equilibrium involving the de- and re-protonation of the considerably acidic alkyne proton of $\mathbf{d}\left(\mathrm{pk}_{\mathrm{A}}=\right.$ $\left.15.61^{18}\right) .{ }^{19}$ The reaction conditions disclosed here are an improvement compared to the state of the art. For example, 1c has been obtained in $93 \%$ conversion before using 10 mol\% TPP, 3 equiv. $\mathbf{c}$ and heating the reaction mixture for $8 \mathrm{~h}$ under refluxing conditions. ${ }^{12}$ However, with base catalysis $\left(\mathrm{KO}^{\mathrm{t}} \mathrm{Bu}\right)$ even better results than those presented here can be achieved. ${ }^{20,21}$

Switching to the weaker Michael acceptor acrylamide (E=-23.54 for N,Ndimethylacrylamide), ${ }^{17}$ no useful conversions on any account are obtained. However, TMTPP performs best, giving 61 and $74 \%$ conversion with 1-propanol and allyl alcohol after $24 \mathrm{~h}$. To illustrate that the reaction does not stop after $24 \mathrm{~h}$ the conversions were re-checked after $21 \mathrm{~d}$. After this time with TMTPP as the catalyst, conversions of $44 \%$ (3a), 92\% (3b), $98 \%$ (3c) and $91 \%$ (3d) are obtained. No indications for $a z a$-Michael reactions potentially leading to polyamide 3 like structures were observed. ${ }^{22}$ A more efficient transformation of acrylamide can be obtained with base-catalysis. Using activated potassium carbonate, a reaction temperature of $40{ }^{\circ} \mathrm{C}$ and $4 \mathrm{~h}$ reaction time give typically better conversions than those reported herein with nucleophiles. $^{23}$

Next, difunctional divinyl sulfone was tested as the strongest Michael acceptor $(E=-18.36$, for phenyl vinyl sulfone $)^{17}$ under investigation. In distinction from the experiments described above, three equivalents of the alcohol were used. In general, the different catalysts perform very similar in this reaction giving high double bond conversions of about $80 \%$ after already 1 h. ${ }^{24}$ 


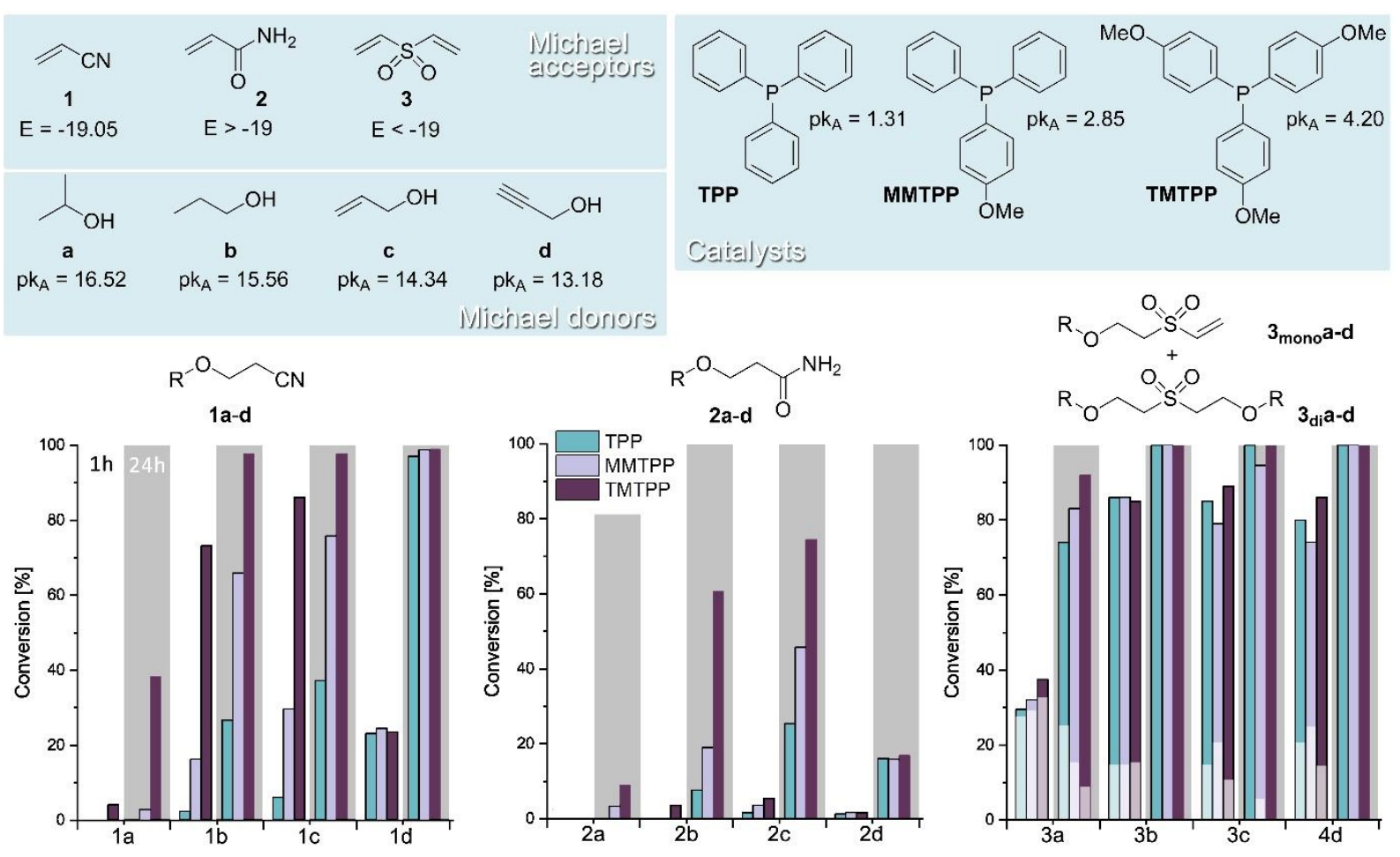

Figure 1. Above: Michael acceptors, Michael donors and catalysts used in this study; $\mathrm{pK}_{\mathrm{A}}$ (respectively $\mathrm{pK}_{\mathrm{A}}$ of the conjugated acid in case of phosphines) calculated using the $\mathrm{pK}_{\mathrm{A}}$ prediction platform (neural network result for solvent $\mathrm{H}_{2} \mathrm{O}$ ) available at pka.luo-group.com [Ref. 18]; below: Conversion of the oxa-Michael reaction of acrylonitrile (left), acrylamide (middle) and divinyl sulfone (right; double bond conversion is given; light sections

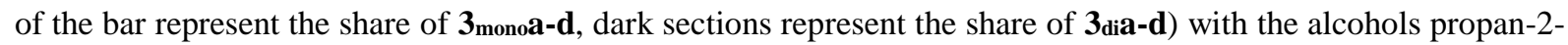
ol (a), propan-1-ol (b), prop-2-en-1-ol (c) and prop-2-yn-1-ol (d) catalyzed by triphenylphosphine (TPP), (4methoxyphenyl)diphenylphosphine (MMTPP) and tris-(4-methoxyphenyl)phosphine (TMTPP). Reaction conditions: 1 equiv. Michael acceptor; 2 equiv. alcohol (in case of 3, 3 equiv. alcohol); 1 mol\% catalyst (in respect to Michael acceptor); $1 \mathrm{~h}$ and $24 \mathrm{~h}$ (bars above grey boxes) at room temperature $\left(23{ }^{\circ} \mathrm{C}\right)$; no solvent used.

A mixture of mono- (3monoa-d) and di-adducts (3.ia-d) are observed and only in case of 2propanol also divinyl sulfone is still present. With 2-propanol a slight but significant influence of the catalyst choice on the conversion is observed (Figure 1). With all other (more acidic) alcohols, the conversion is reaching completeness after $24 \mathrm{~h}$. Why MMTPP is performing slightly worse than TPP as indicated by the double-bond conversion and by the higher share of the mono-adduct $\mathbf{3}$ monoa-d after $1 \mathrm{~h}$ reaction time is not clear. The reaction of $\mathbf{3}$ with 3 equiv. $\mathbf{a}$ or c catalyzed with $10 \mathrm{~mol} \% \mathrm{TPP}$ at $40{ }^{\circ} \mathrm{C}$ using dichloromethane $([\mathrm{DVS}]=0.55 \mathrm{M})$ as solvent has been described. 3a was obtained in a $76: 13$ mixture of $\mathbf{3}_{\text {mono }} \mathbf{a}$ and $\mathbf{3}_{\mathrm{dia}}$ and $\mathbf{3} \mathbf{c}$ in a $11: 89$ mixture of $\mathbf{3}$ monoc and $\mathbf{3}_{\mathrm{dic}}{ }^{19}$ The herein disclosed results highlight that solvent-free conditions are particularly effective and allow for reducing the catalyst loading by the factor of 10 , thereby obtaining a higher share of $\mathbf{3}_{\mathbf{d i a}}$ and full conversion towards $\mathbf{3}_{\mathbf{d i c}} \mathbf{c}$. Interestingly, the catalytic activity of TPP in reactions with $\mathbf{3}$ as the Michael acceptor is only slightly lower than the activity of the methoxy-substituted congeners.

As an example for acrylates as Michael acceptors, the performance of the catalysts in the oxaMichael addition polymerization of 2-hydroxyethyl acrylate (HEA, 4) was investigated. ${ }^{25,26,27}$ The catalyst loading was increased to $5 \mathrm{~mol} \%$, because $1 \mathrm{~mol} \%$ was not sufficient to obtain satisfying conversions. The reaction mixture consisting of $\mathbf{4}$ and the catalyst was either stirred at room temperature or put in a drying chamber operated at $80{ }^{\circ} \mathrm{C}$. Aliquots of the reaction mixture were sampled after 1 and $24 \mathrm{~h}$ and analyzed by ${ }^{1} \mathrm{H}-\mathrm{NMR}$ spectroscopy and size exclusion chromatography (SEC). Results are shown in Figure 2. 

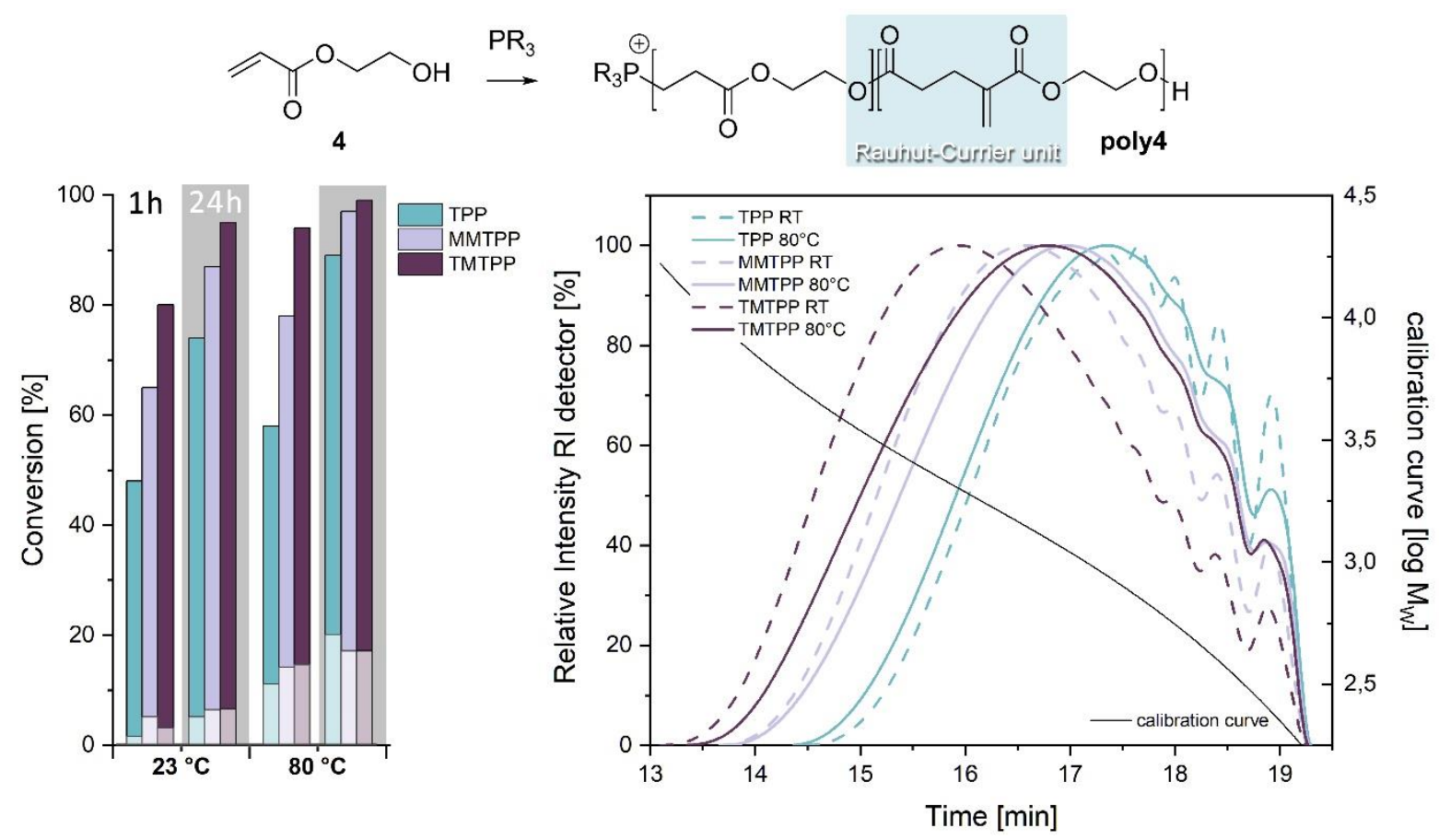

Figure 2. left: double bond conversion of the polymerization of 4 initiated by 5 mol\% TPP, MMTPP or TMTPP after $1 \mathrm{~h}$ at room temperature $\left(23^{\circ} \mathrm{C}\right)$ and at $80^{\circ} \mathrm{C}$ as well as after $24 \mathrm{~h}$ at $23{ }^{\circ} \mathrm{C}$ and at $80{ }^{\circ} \mathrm{C}$, light sections of the bars represent the share of Rauhut-Currier repeat units; right: size exclusion chromatograms (in THF, relative to poly(styrene) standards) of poly4 prepared with 5 mol\% TPP, MMTPP or TMTPP using a reaction time of $24 \mathrm{~h}$ and a reaction temperature of $23{ }^{\circ} \mathrm{C}$ (dashed lines) or $80{ }^{\circ} \mathrm{C}$ (full lines).

After $1 \mathrm{~h}$ at room temperature, an impact of the catalysts on the double bond conversion is evident. TPP gave a double bond conversion of $48 \%$, while MMTPP and TMTPP performed better with 67 and $80 \%$. After $24 \mathrm{~h}$ at room temperature conversions increased to $74 \%$ (TPP), $85 \%$ (MMTPP) and $90 \%$ (TMTPP). Performing the reaction at $80^{\circ} \mathrm{C}$ leads to higher double bond conversions than at room temperature. After $1 \mathrm{~h}$ reaction time conversions of $58 \%$ (TPP), $78 \%$ (MMTPP) and $94 \%$ (TMTPP) were obtained. Prolonging the reaction time to $24 \mathrm{~h}$ led to high double bond conversion of $89 \%$ in case of TPP and $97 \%$ and $99 \%$ in the cases of MMTPP and TMTPP. Molar mass distributions of the polymers prepared with a reaction time of $24 \mathrm{~h}$ were determined by SEC. First, the polymerizations conducted at room temperature are discussed. As expected from the trend in double bond conversion, the number average molar mass $\left(M_{n}\right)$ of poly4 increases according to the activity of the initiator. The $M_{n}$ values nearly doubled when going from TPP $(660 \mathrm{~g} / \mathrm{mol}$, dispersity $Đ=1.5)$ to TMTPP $(1160 \mathrm{~g} / \mathrm{mol}, Ð=$ 1.8) with MMTPP $(910 \mathrm{~g} / \mathrm{mol}, \mathrm{D}=1.7)$ lying in about the middle of these two values. Turning to the results obtained for the polymerization conducted at $80{ }^{\circ} \mathrm{C}$ it is revealed that poly4 prepared with TPP is characterized by only a slightly higher $\mathrm{M}_{\mathrm{n}}$ value of $680 \mathrm{~g} / \mathrm{mol}$ than poly4 from the room temperature reaction. MMTPP and TMTPP derived poly4 exhibit even lower $\mathrm{M}_{\mathrm{n}}$-values ( 820 and $890 \mathrm{~g} / \mathrm{mol}, \mathrm{Ð}=1.7$ and 1.8) than obtained in the room temperature reaction. Considering the distinctly higher double bond conversions at $80{ }^{\circ} \mathrm{C}$, these findings point to another double bond consuming reaction beside the $o x a$-Michael reaction. Evaluation of the NMR spectra indicate, among repeating units from oxa-Michael and transesterification reactions, ${ }^{28,29}$ the presence of Rauhut-Currier derived linkages. ${ }^{30,31,32}$ This repeat unit is characterized by peaks at 6.22 and $5.64 \mathrm{ppm}$ in the ${ }^{1} \mathrm{H}-\mathrm{NMR}$ spectrum and at 126.6, 33.0, 27.3 ppm in the ${ }^{13} \mathrm{C}$-NMR spectrum of poly4 (see Supporting Information) and its share is with approximately $17-20 \%$ higher in polymers prepared at $80{ }^{\circ} \mathrm{C}$ (Figure 2). The formation of this repeat unit consumes two equivalents of acrylates and thus, disproportionally decreases the 
quantity of acrylate groups in relation to alcohol groups. Consequently, the originally ideal stoichiometry of Michael acceptors and Michael donors is changed in favor of alcohols. This eventually results in lower molecular mass distributions in cases in which more Rauhut-Currier repeat units are formed. In comparison, poly4 has been prepared with nucleophilic catalysis using $10 \mathrm{~mol} \% \mathrm{~N}$-heterocyclic carbenes such as 1,3,4-triphenyl-4,5-dihydro-1H-1,2,4-triazol5-ylidene or 1,3-bis(2,6-diisopropylphenyl)imidazol-2-ylidene. The polymerization was carried out at room temperature for $24 \mathrm{~h}$ and no solvent was used. The resulting reaction mixture was dissolved in dichloromethane and precipitated from diethyl ether resulting in about $50 \%$ polymer yield featuring $\mathrm{M}_{\mathrm{n}}$ values of $1500-1800 \mathrm{~g} / \mathrm{mol}^{28}$

Next, the oxidation stability of the catalysts was tested. For this purpose, the three different phosphines were exposed to air for $14 \mathrm{~d}$ in dark conditions. Four different conditions were chosen. Undissolved solid samples and samples dissolved in chloroform or in 1-hexanol were kept at room temperature and solutions in 1-hexanol were also heated at $80{ }^{\circ} \mathrm{C}$. The reaction mixture was then investigated via ${ }^{31} \mathrm{P}-\mathrm{NMR}$ spectroscopy. Under all conditions, the formation of the corresponding phosphine oxide derivative as the only decomposition product was observed. Results, shown in Figure 3, reveal that oxidation stability is decreasing in the order TPP > MMTPP > TMTPP, which is in line with electrochemical studies showing a decrease of the oxidation potential from $1.400 \mathrm{~V}$ (TPP) to $1.050 \mathrm{~V}$ (TMTPP). ${ }^{33}$
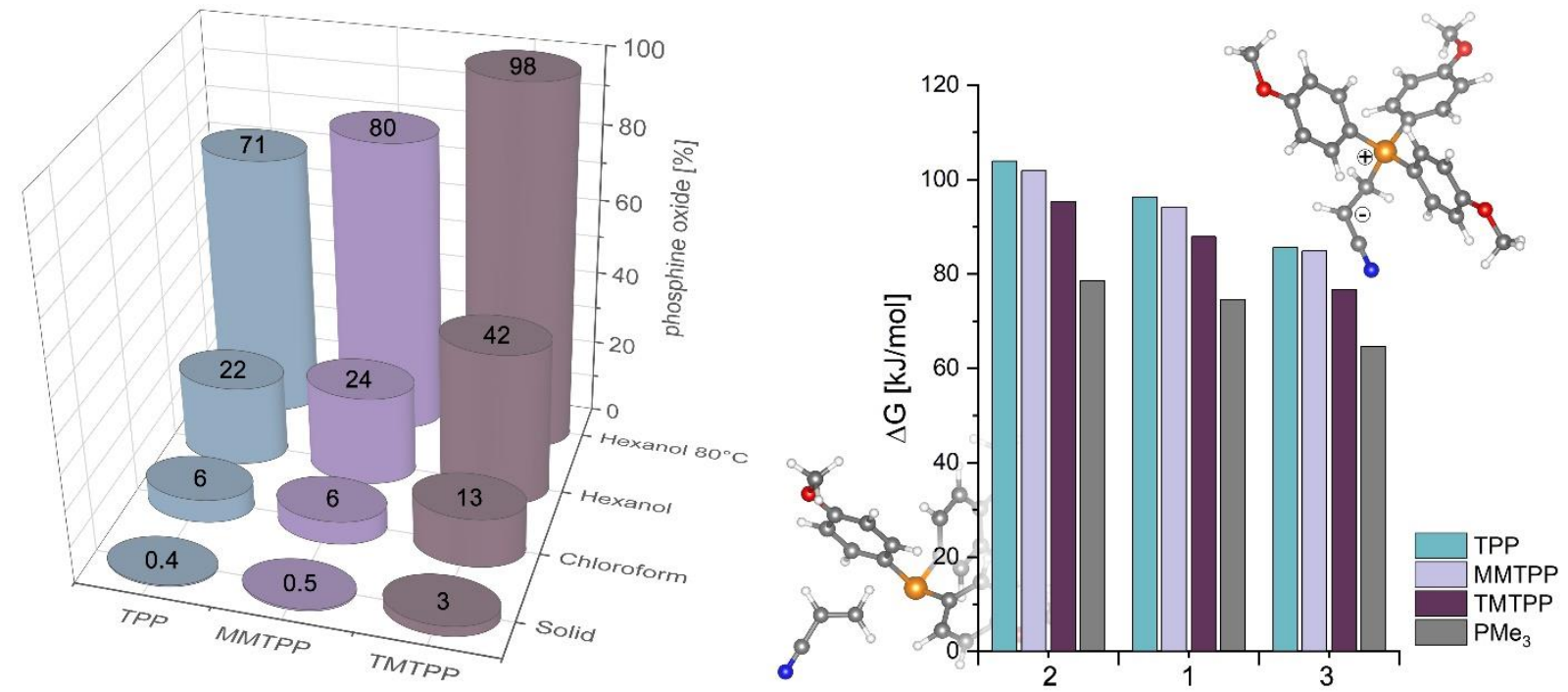

Figure 3. left: Oxidation stability of the phosphines. Phosphine oxide content in $\%$ as determined by ${ }^{31} \mathrm{P}-\mathrm{NMR}$ spectroscopy of a solid sample, samples dissolved in chloroform and 1-hexanol (after $14 \mathrm{~d}$, stored at room temperature in the dark) and in 1-hexanol (after $14 \mathrm{~d}$, stored at $80^{\circ} \mathrm{C}$ in the dark). right: Relative stabilities of the zwitterions formed upon reaction of Michael acceptors 1-3 with the phosphines (the cartoon shows the structures of the acrylonitrile TMTPP reaction).

Furthermore, the share of phosphine oxide is dependent on the oxygen solubility in the solvent, as indicated by the experiments in chloroform and 1-hexanol exhibiting the higher oxygen solubility. ${ }^{34}$ To obtain further insight, the SOMO energies of the radical cations of the phosphines under investigation were calculated by density functional theory (DFT), namely B3LYP-def2-TZVPPD. According to criterion introduced by Stewart et al. postulating air stability of phosphines when the SOMO energy is higher than $-10 \mathrm{eV}$, the three derivatives should be air stable. ${ }^{11}$ However, the SOMO energies decrease within the series from $-9.60 \mathrm{eV}$ (TPP, -9.50 according to Ref. 11) to -9.18 (MMTPP) and -8.59 (TMTPP) suggesting TMTPP to exhibit the highest oxidation stability within the series, the opposite what was observed 
experimentally. Therefore, the oxidation stability of the phosphines discussed here cannot be described by evaluating their SOMO energies as suggested previously. All in all, experiments demonstrate that the oxidation stability of all phosphines under investigation can be considered sufficient for running reactions (under typically employed reaction conditions, i.e. reaction temperatures and times not exceeding $80{ }^{\circ} \mathrm{C}$ and $24 \mathrm{~h}$ ) without the unconditional need to exclude oxygen.

A first hint for rationalizing the different reactivity of the different phosphines can be retrieved from the $\mathrm{pK}_{\mathrm{A}}$ value of their conjugated acids. Substitution of the aromatic rings with methoxy groups increases the $\mathrm{pK}_{\mathrm{A}}$ value from 1.31 (TPP) to 4.20 (TMTPP) (Figure 1). Methyl cation affinities (MCA) which can be used as descriptors for the nucleophilicity of a compound were calculated by Lindner et. al. who suggested TMTPP $(651.0 \mathrm{~kJ} / \mathrm{mol})$ to be a stronger Lewis base than TPP $(618.7 \mathrm{~kJ} / \mathrm{mol}) .{ }^{35}$ However, for $\mathrm{PMe}_{3}$, discussed as a model for aliphatic phosphines, a distinctly lower MCA of $604.2 \mathrm{~kJ} / \mathrm{mol}$ was calculated. This is in contrast to experimental data as $\mathrm{PMe}_{3}$ is known as a more active catalyst for $o x a$-Michael additions than arylphosphines. ${ }^{8,12}$ Apparently, the MCA is not correlating with the phosphines activities in conjugate addition reactions. Another approach for assessing the nucleophilicity of the phosphines is to compare their HOMO energy, which was also assessed by DFT. ${ }^{36,37}$ The nucleophilicity should increase with increasing $\sigma$-donor ability of the phosphines or, in other words, with increasing s-character of the orbital containing the lone pair, which should also be the HOMO of the molecule. A higher s-character of the HOMO, going in hand with a higher energy level of the HOMO, is thus indicative for a higher nucleophilicity. Accordingly, the HOMO energies have been calculated and increase from-5.91 eV (TPP) to $-5.73 \mathrm{eV}$ (MMTPP) and $-5.42 \mathrm{eV}$ (TMTPP). A comparison of the orbital distributions of the arylphosphines reveals that the HOMO of all phosphines under investigation has a significant phosphorous character (visual representations in SI). However, considering the HOMO energy of $\mathrm{PMe}_{3}$ which is calculated to be as low as $6.10 \mathrm{eV}$, it is obvious that also this approach fails in sufficiently describing the activity of phosphines in catalyzing oxa-Michael reactions. To resolve this issue, the Gibbs' free energy $(\triangle \mathrm{G})$ of the reaction of TPP, MMTPP, TMTPP and $\mathrm{PMe}_{3}$ with acrylonitrile leading to zwitterion formation (Figure 3, right) was calculated in chloroform. The Michael acceptor affinity (MAA) of the nucleophiles is then given by the Gibbs' free energy of the back reaction. ${ }^{35}$ The respective energy differences calculated on B3LYP/def2-TZVPPD level are $-96.3 \mathrm{~kJ} / \mathrm{mol}$ (TPP), -94.2 $\mathrm{kJ} / \mathrm{mol}$ (MMTPP), $-87.9 \mathrm{~kJ} / \mathrm{mol}$ (TMTPP) and $-74.5 \mathrm{~kJ} / \mathrm{mol}\left(\mathrm{PMe}_{3}\right)$ in favor of the educts acrylonitrile and phosphine. Accordingly, $\mathrm{PMe}_{3}$ forms the in relation most stable and TPP the most unstable zwitterion within the series. The stability trend of the zwitterions based on acrylamide and divinyl sulfone is the same (Figure 3, right). The different reactivity of the three Michael acceptors is apparent from the relative stabilities of the zwitterion. Acrylamide gives the least stable (MAA with TPP is $-103.9 \mathrm{~kJ} / \mathrm{mol}$ ) and DVS the most stable zwitterion (MAA with TPP: $-85.6 \mathrm{~kJ} / \mathrm{mol}$ ). Consequently, such calculated Michael acceptor affinities correlate with experimental results and are suited to reflect the actual activity of the phosphines under investigation. This is reasonable because the position of the thermodynamic equilibrium of unreacted Michael acceptor and donor and the corresponding zwitter-ion $\mathbf{i}$ is believed to be decisive for the efficacy of the subsequent reaction, protonation of $\mathbf{i}$ by the alcohol resulting in the formation of io-pair ii (Scheme 1). ${ }^{38}$ In turn, the $\mathrm{pK}_{\mathrm{A}}$ value of the alcohol is another important parameter for the speed of the overall reaction. The alcohol's acidity is determining how efficiently $\mathbf{i}$ is transformed into the ion pair ii (Scheme 1) being the actual entry point into the catalytic cycle of the oxa-Michael reaction. Accordingly, the reactivity trend observed for the different alcohols under investigation is rationalized. Note that although a two step-process 
is discussed herein, it is also conceivable that the reaction towards ii proceeds via a single transition state involving the Michael acceptor, the Michael donor and the alcohol. Furthermore, the different nucleophilicity of the generated alkoxides might play an additional role. However, it has been shown that the nucleophilicity of alkoxides differs only moderately. ${ }^{39}$ Therefore, this effect is considered to be less important for the explanation of the relative characteristics of the reactions than the factors discussed above.

\section{Conclusion}

The activity of differently substituted triarylphosphines in the $o x a$-Michael addition of alcohols to electron deficient olefins was investigated. In general, the activity increases with increasing methoxy-substitution in the order TPP < MMTPP < TMTPP. The activity order was rationalized based on DFT calculations by an increasing stationary concentration of the primary reaction product, the corresponding $\beta$-phosphonium $\alpha$-carbanionic zwitterion, when using arylphosphines with more electron donating substituents. Besides the catalyst, the second decisive factor for the speed of the reaction is the acidity of the alcohol as the efficacy of the secondary reaction, where the zwitterion reacts with the alcohol, increases when more acidic alcohols are used. Moreover, concentrated conditions or the omission of solvents is beneficial for this reaction. In summary, the better catalyst TMTPP is particularly useful for reacting weak Michael acceptors and/or less acidic alcohols. Phosphine loadings of only $1 \mathrm{~mol} \%$ in respect to the Michael acceptor are in many cases sufficient to provide full conversion in $24 \mathrm{~h}$ at room temperature. With good Michael acceptors and/or acidic alcohols the catalytic activity of TPP becomes competitive to the one of the more expensive TMTPP. Furthermore, TMTPP is somewhat more sensitive to oxidation in air than TPP. Nevertheless, exclusion of air is, in contrast to trialkylphosphines, not mandatory. Oxidation under typical reaction conditions (reaction time not longer than $24 \mathrm{~h}$ and reaction temperature below $80^{\circ} \mathrm{C}$ ) is slow and can be considered as unproblematic.

\section{Experimental}

\section{General Information}

All experiments were performed under ambient conditions. Chemicals were purchased from Sigma Aldrich, Carl Roth, Merck or TCI and were used as received. The catalysts TPP and TMTPP were purchased from Sigma Aldrich. MMTPP was prepared according to literature. ${ }^{40}$ Stabilizers present in the Michael acceptors were not removed. ${ }^{1} \mathrm{H}$ - and ${ }^{13} \mathrm{C}$ - NMR spectra were recorded on a Bruker Avance $300 \mathrm{MHz}$ spectrometer at $25{ }^{\circ} \mathrm{C}\left({ }^{1} \mathrm{H}: 300.36 \mathrm{MHz} ;{ }^{13} \mathrm{C}: 75.53\right.$ $\mathrm{MHz}$ ). Chemical shifts $\delta$ are given in ppm relative to the residual protons and carbons of the deuterated solvent. $\left(\mathrm{CHCl}_{3}\right.$ : $7.26 \mathrm{ppm}$ and $77.16 \mathrm{ppm}$, DMSO: 2.50 and 39.52 for ${ }^{1} \mathrm{H}$ and ${ }^{13} \mathrm{C}$, respectively). ${ }^{31} \mathrm{P}$ measurements were performed on a Varian Inova $500 \mathrm{MHz}$ instrument operating at $202.547 \mathrm{MHz}$. Chemical shifts are reported in ppm relative to an external standard $\left(85 \% \mathrm{H}_{3} \mathrm{PO}_{4}\right)$. Spectra are ${ }^{1} \mathrm{H}$-decoupled and as delay time (d1) $25 \mathrm{~s}$ was set. Deuterated solvents were obtained from Cambridge Isotope Laboratories Inc. Size exclusion chromatography (SEC) was performed on a system provided by Shimadzu (equipped with two

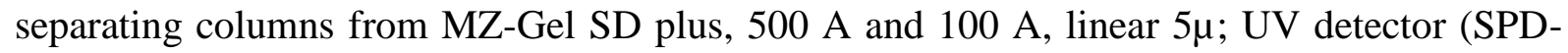
20A) and RI detector (RID-20A)) using THF as eluent. Poly(styrene) standards in the range of 350 to $17800 \mathrm{~g} / \mathrm{mol}$ purchased from Polymer Standard Service were used for calibration. 


\section{Computational Details}

All calculations were run with the TURBOMOLE program (version 7.4.1). ${ }^{41}$ Geometries were pre-optimized using the $\mathrm{PBE}^{42}$ functional, the def2-SVPD ${ }^{43,44}$ basis set and $\mathrm{D}^{45}$-dispersion correction. All structures were then re-optimized using the hybrid functional B3LYP $46,47,48,49$ D3 with the def2-TZVPPD basis set. For gas phase calculations, temperature effects (298 K) and zero-point energies have been approximated by the rigid-rotor-harmonic oscillator (RRHO) approximation. The zero-point energies have been scaled by a factor of 1.0030 (B3LYP/def2TZVPPD) and 1.0302 (PBE/def2-SVPD) to account for anharmonic effects. ${ }^{50}$ Solvent effects of chloroform have been considered for calculation of Gibbs free energy $(\Delta \mathrm{G})$ of zwitterion formation and were calculated by the conductor like screening model (COSMO $)^{51,52}$ with a dielectric constant of 4.8 and a radius of 3.17. Our best estimate for calculation of zwitterion energies resulted in using B3LYP-D3 /TZVPPD + $\Delta$ solv (B3LYP-D3) + ZPE, temp (PBED3/def2-SVPD).

\section{General procedure for oxa-Michael additions}

Alcohol (2.0 equiv. for mono-functionalized Michael acceptors, 3.0 equiv. for 3 ) and catalyst ( 0.01 equiv.) were added to a $4 \mathrm{~mL}$ sealed tube. Then, the Michael acceptor was added, and the reaction mixture was stirred at room temperature or at $80{ }^{\circ} \mathrm{C}$. The reaction progress was monitored by ${ }^{1} \mathrm{H}$-NMR spectroscopy after 1 and $24 \mathrm{~h}$. All experiments were performed at least three times.

\section{Oxa-Michael addition polymerization of 2-hydroxyethyl acrylate (4)}

A $4 \mathrm{~mL}$ glass tube was charged with phosphine (0.05 equiv) and 4 (1.0 equiv., $0.1 \mathrm{~g}, 0.861$ mmol) and sealed. The reaction mixture was stirred at room temperature or at $80{ }^{\circ} \mathrm{C}$. Samples taken after either $1 \mathrm{~h}$ or $24 \mathrm{~h}$ were evaluated by ${ }^{1} \mathrm{H}-\mathrm{NMR}$ spectroscopy and SEC. All experiments were performed at least three times.

Acknowledgment. Funding by the Christian Doppler Research Association (Austrian Federal Ministry for Digital and Economic Affairs and the National Foundation for Research, Technology and Development) is gratefully acknowledged. We thank Petra Kaschnitz for acquiring ${ }^{31} \mathrm{P}-\mathrm{NMR}$ spectra.

Supporting Information containing experimental details, data in tabular form, NMR spectra and xyz files of calculated structures is available.

\section{References}

\footnotetext{
${ }^{1}$ Guo, H.; Fan, Y. C.; Sun, Z.; Wu, Y.; Kwon, O. Phosphine Organocatalysis. Chem. Rev. 2018, 118, 1004910293. DOI: 10.1021/acs.chemrev.8b00081

${ }^{2}$ Methot, J. L.; Roush, W. R. Nucleophilic Phosphine Organocatalysis. Adv. Synth. Catal. 2004, 346, $1035-1050$. DOI: $10.1002 /$ adsc. 200404087

${ }^{3}$ Xiao, Y.; Sun, Z.; Guo, H.; Kwon, O. Chiral Phosphines in Nucleophilic Organocatalysis. Beilstein J. Org. Chem. 2014, 10, 2089-2121. DOI: $10.3762 /$ bjoc. 10.218

${ }^{4}$ Gimbert, C.; Lumbierres, M.; Marchi, C.; Moreno-Mañas, M.; Sebastián, R. M.; Vallribera, A. Michael Additions Catalyzed by Phosphines. An Overlooked Synthetic Method. Tetrahedron 2005, 61, 8598-8605. DOI: $\underline{10.1016 / \text { j.tet.2005.07.005 }}$

${ }^{5}$ Horner, L.; Jurgeleit, W.; Klüpfel, K. Zur Anionotropen Polymerisationsauslösung Bei Olefinen Tertiäre Phosphine III. Justus Liebigs Ann. Chem. 1955, 591, 108-117. DOI: 10.1002/jlac.19555910107
} 
${ }^{6}$ Morita, K.; Suzuki, Z.; Hirose, H. A Tertiary Phosphine-Catalyzed Reaction of Acrylic Compounds with Aldehydes. Bull. Chem. Soc. Jpn. 1968, 41, 2815-2815. DOI: 10.1246/bcsj.41.2815

${ }^{7}$ Stewart, I. C.; Bergman, R. G.; Toste, F. D. Phosphine-Catalyzed Hydration and Hydroalkoxylation of Activated Olefins: Use of a Strong Nucleophile to Generate a Strong Base. J. Am. Chem. Soc. 2003, 125, 8696-8697. DOI: $\underline{10.1021 / \mathrm{ja} 035232 \mathrm{n}}$

${ }^{8}$ Inanaga, J.; Baba, Y.; Hanamoto, T. Organic Synthesis with Trialkylphosphine Catalysts. Conjugate Addition of Alcohols to $\alpha, \beta$-Unsaturated Alkynic Acid Esters. Chem. Lett. 1993, 241-244. DOI: 10.1246/cl.1993.241

${ }^{9}$ Barder, T. E.; Buchwald, S. L. Rationale Behind the Resistance of Dialkylbiaryl Phosphines toward Oxidation by Molecular Oxygen. J. Am. Chem. Soc. 2007, 129, 5096-5101. DOI: 10.1021/ja0683180

10 Buckler, S. A. Autoxidation of Trialkylphosphines. J. Am. Chem. Soc. 1962, 84, 3093-3097. DOI: $\underline{10.1021 / \mathrm{ja} 00875 \mathrm{a} 011}$

${ }^{11}$ Stewart, B.; Harriman, A.; Higham, L. J. Predicting the Air Stability of Phosphines. Organometallics 2011, 30, 5338-5343. DOI: 10.1021/om200070a

${ }^{12}$ Liu, H.-L.; Jiang, H.-F.; Wang, Y.-G. Triphenylphosphine-Catalyzed Michael Addition of Alcohols to Acrylic Compounds. Chinese J. Chem. 2007, 25, 1023-1026. DOI: 10.1002/cjoc.200790163

${ }^{13}$ Wang, Q.; Huan, F.; Shen, H.; Xiao, J. C.; Gao, M.; Yang, X.; Murahashi, S. I.; Chen, Q. Y.; Guo, Y. Organocatalytic Reactions of $\alpha$-Trifluoromethylated Esters with Terminal Alkenes at Room Temperature. J. Org. Chem. 2013, 78, 12525-12531. DOI: 10.1021/j0402212j

${ }^{14}$ Teng, J. J.; Qiao, Y. H.; Zhang, Q.; Li, C. H.; Huang, M. Tris(4-Methoxylphenyl)Phosphine-Catalyzed C-C Bond Formation Reaction: Mutual Addition of Aromatic Aldehydes and Ethyl Acrylate. Synth. Commun. 2013, 43, 848-858. DOI: 10.1080/00397911.2011.610551

${ }^{15}$ Lindner, C.; Tandon, R.; Liu, Y.; Maryasin, B.; Zipse, H. The Aza-Morita-Baylis-Hillman Reaction of Electronically and Sterically Deactivated Substrates. Org. Biomol. Chem. 2012, 10, 3210-3218. DOI: $\underline{10.1039 / \mathrm{c} 2 \mathrm{ob} 07058 \mathrm{~h}}$

${ }^{16}$ Ramachary, D. B.; Prabhakar Reddy, T.; Suresh Kumar, A. Organocatalytic Umpolung Annulative Dimerization of Ynones for the Synthesis of 5-Alkylidene-2-Cyclopentenones. Org. Biomol. Chem. 2017, 15, 9785-9789. DOI: $10.1039 / \mathrm{c} 7 \mathrm{ob} 02424 \mathrm{j}$

${ }^{17}$ Allgäuer, D. S.; Jangra, H.; Asahara, H.; Li, Z.; Chen, Q.; Zipse, H.; R. Ofial, A.; Mayr, H. Quantification and Theoretical Analysis of the Electrophilicities of Michael Acceptors. J. Am. Chem. Soc. 2017, 139, 13318-13329. DOI: $10.1021 / \mathrm{jacs} .7 \mathrm{~b} 05106$

${ }^{18}$ calculated using the pKa prediction platform (neural network result for solvent $\mathrm{H} 2 \mathrm{O}$ ) available at pka.luogroup.com see: Yang, Q.; Li, Y.; Yang, J.-D.; Liu, Y.; Zhang, L.; Luo, S.; Cheng, J.-P. Holistic Prediction of pKa in Diverse Solvents Based on Machine Learning Approach, Angew. Chem. Int. Ed. 2020, 59, 19282-19291. DOI: $\underline{10.1002 / a n i e .202008528}$

${ }^{19}$ Strasser, S.; Slugovc, C. Nucleophile-Mediated Oxa-Michael Addition Reactions of Divinyl Sulfone - a ThiolFree Option for Step-Growth Polymerisations. Catal. Sci. Technol. 2015, 5, 5091-5094. DOI: 10.1039/c5cy01527h ${ }^{20}$ Bayer, O. Die Chemie des Acrylnitrils. Angew. Chem. 1949, 61, 229-241. DOI: 10.1002/ange. 19490610602

${ }^{21}$ Thiyagarajan, S.; Krishnakumar, V.; Gunanathan, C. KOtBu-Catalyzed Michael Addition Reactions Under Mild and Solvent-Free Conditions. Chem. Asian J. 2020, 15, 518-523. DOI: 10.1002/asia.201901647

${ }^{22}$ Edinger, D.; Weber, H.; Žagar, E.; Pahovnik, D.; Slugovc, C. Melt-polymerization of acrylamide initiated by nucleophiles: a route towards highly branched and amorphous polyamide 3. ACS Appl. Polym. Mater. 2021. DOI: $\underline{10.1021 / \text { acsapm. } 1 \mathrm{c} 00084}$

${ }^{23}$ Liu, Q.; Zhou, H.; Wang, J. Oxa-Michael addition of acrylamide: synthesis of $\beta$-alkoxypropionamide. Huaxue Tongbao 2018, 81, 604-609.

${ }^{24}$ Strasser, S.; Wappl, C.; Slugovc, C. Solvent-Free Macrocyclisation by Nucleophile-Mediated Oxa-Michael Addition Polymerisation of Divinyl Sulfone and Alcohols. Polym. Chem. 2017, 8, 1797-1804. DOI: 10.1039/c7py00152e

${ }^{25}$ Saegusa, T.; Kobayashi, S.; Kimura, Y. Hydrogen-Transfer Polymerization of Hydroxyalkyl Acrylates. Macromolecules 1975, 8, 950-952. DOI: 10.1021/ma60048a051

${ }^{26}$ Jiang, Q.; Zhang, Y. L.; Du, Y.; Tang, M.; Jiang, L.; Huang, W.; Yang, H.; Xue, X.; Jiang, B. Preparation of Hyperbranched Polymers by Oxa-Michael Addition Polymerization. Polym. Chem. 2020, 11, 1298-1306. DOI: $\underline{10.1039 / \mathrm{c} 9 \mathrm{py} 01686 \mathrm{~d}}$

${ }^{27}$ Yang, H.; Zuo, Y.; Zhang, J.; Song, Y.; Huang, W.; Xue, X.; Jiang, Q.; Sun, A.; Jiang, B. Phosphazene-Catalyzed Oxa-Michael Addition Click Polymerization. Polym. Chem. 2018, 9, 4685-4800. DOI: 10.1039/c8py01089g

${ }^{28}$ Matsuoka, S. I.; Namera, S.; Suzuki, M. Oxa-Michael Addition Polymerization of Acrylates Catalyzed by NHeterocyclic Carbenes. Polym. Chem. 2015, 6, 294-301. DOI: 10.1039/c4py01184h

Page 10 
${ }^{29}$ Ratzenböck, K.; Pahovnik, D.; Slugovc, C. Step-Growth Polymerisation of Alkyl Acrylates via Concomitant Oxa-Michael and Transesterification Reactions . Polym. Chem. 2020, 11, 7476-7480. DOI: 10.1039/D0PY01271H ${ }^{30}$ Aroyan, C. E.; Dermenci, A.; Miller, S. J. The Rauhut-Currier reaction: a history and its synthetic application. Tetrahedron 2009, 65, 4069-4084. DOI: 10.1016/j.tet.2009.02.066

${ }^{31}$ Gibas, M.; Korytkowska-Walach, A. Polymerization of 2-hydroxyethyl acrylate and methacrylate via Michaeltype addition. Polym. Bull. 2003, 51, 17-22. DOI: 10.1007/s00289-003-0191-7

${ }^{32}$ Kadokawa, J.-i, Kaneko, Y.; Yamada, S.; Ikuma, K.; Tagaya, H.; Chiba, K. Synthesis of hyperbranched polymers via proton-transfer polymerization of acrylate monomer containing two hydroxy groups. Macromol. Rapid Commun. 2000, 21, 362-368. DOI: 10.1002/(SICI)1521-3927(20000401)21:7<362::AIDMARC362>3.0.CO;2-F

${ }^{33}$ Berchadsky, Y.; Tordo, P.; Gronchi, G.; Culcasi, M. Anodic Behavior of Crowded Triarylphosphines. ESR Study of Triarylphosphoniumyl Radicals, Ar3P•+. J. Org. Chem. 1991, 56, 3537-3542. DOI: $\underline{10.1021 / j 000011 \mathrm{a} 018}$

${ }^{34}$ Sato, T.; Hamada, Y.; Sumikawa, M.; Araki, S.; Yamamoto, H. Solubility of Oxygen in Organic Solvents and Calculation of the Hansen Solubility Parameters of Oxygen. Ind. Eng. Chem. Res. 2014, 53, 19331-19337. DOI: 10.1021/ie502386t

${ }^{35}$ Lindner, C.; Tandon, R.; Maryasin, B.; Larionov, E.; Zipse, H. Cation Affinity Numbers of Lewis Bases. Beilstein J. Org. Chem. 2012, 8, 1406-1442. DOI: 10.3762/bjoc.8.163

36 Dunne, B. J.; Morris, R. B.; Orpen, A. G. Structural systematics. Part 3. Geometry deformations in triphenylphosphine fragments: A test of bonding theories in phosphine complexes. J. Chem. Soc. Dalton Trans. 1991, 653-661. DOI: 10.1039/DT9910000653

37 Palau, C.; Berchadsky, Y.; Chalier, F.; Finet, J.-P.; Gronchi, G.; Tordo, P. Tris(monochlorophenyl)- and Tris(dichlorophenyl)phosphines: Molecular Geometry, Anodic Behavior, and ESR Studies. J. Phys. Chem. 1995, 99, 158-163. DOI: 10.1021/j100001a028

${ }^{38}$ Wang, C.; Chenze, Q. Mechanistic insights into N- or P- centered nucleophile promoted thiol-vinylsulfone Michael addition. Tetrahedron, 2013, 69, 5348-5354. DOI: 10.1016/j.tet.2013.04.123

${ }^{39}$ Phan, T. B.; Mayr, H. Comparison of the nucleophilicities of alcohols and alkoxides. Can J. Chem. 2005, 83, 1554-1560. DOI: $10.1139 / \mathrm{v} 05-170$

${ }^{40}$ Bergbreiter, D. E.; Yang, Y. Variable-Temperature NMR Studies of Soluble Polymer-Supported Phosphine Silver Complexes. J. Org. Chem. 2010, 75, 873-878. DOI: 10.1021/jo902427w

${ }^{41}$ TURBOMOLE 7.4.1. www.turbomole.org

${ }^{42}$ Perdew, J. P.; Burke, K.; Ernzerhof, M. Generalized Gradient Approximation Made Simple. Phys. Rev. Lett. 1996, 77, 3865-3868. DOI: 10.1103/PhysRevLett.77.3865

${ }^{43}$ Weigend, F.; Furche, F.; Ahlrichs, R. Gaussian Basis Sets of Quadruple Zeta Valence Quality for Atoms H-Kr. J. Chem. Phys. 2003, 119, 12753-12762. DOI: 10.1063/1.1627293

${ }^{44}$ Rappoport, D.; Furche, F. Property-Optimized Gaussian Basis Sets for Molecular Response Calculations. $J$. Chem. Phys. 2010, 133, 134105. DOI: 10.1063/1.3484283

${ }^{45}$ Grimme, S.; Antony, J.; Ehrlich, S.; Krieg, H. A Consistent and Accurate Ab Initio Parametrization of Density Functional Dispersion Correction (DFT-D) for the 94 Elements H-Pu. J. Chem. Phys. 2010, 132, 154104. DOI: 10.1063/1.3382344.

${ }^{46}$ Becke, A. D. Density-Functional Exchange-Energy Approximation with Correct Asymptotic Behavior. Phys. Rev. A 1988, 38, 3098-3100. DOI: 10.1103/PhysRevA.38.3098

${ }^{47}$ Lee, C.; Yang, W.; Parr, R. G. Development of the Colle-Salvetti Correlation-Energy Formula into a Functional of the Electron Density. Phys. Rev. B 1988, 37, 785-789. DOI: 10.1103/PhysRevB.37.785

${ }^{48}$ Vosko, S. H.; Wilk, L.; Nusair, M. Accurate Spin-Dependent Electron Liquid Correlation Energies for Local Spin Density Calculations: A Critical Analysis. Can. J. Phys. 1980, 58, 1200-1211. DOI: 10.1139/p80-159

${ }^{49}$ Stephens, P. J.; Devlin, F. J.; Chabalowski, C. F.; Frisch, M. J. Ab Initio Calculation of Vibrational Absorption and Circular Dichroism Spectra Using Density Functional Force Fields. J. Phys. Chem. 1994, 98, $11623-11627$. DOI: 10.1021/j100096a001

${ }^{50}$ Kesharwani, M. K.; Brauer, B.; Martin, J. M. L. Frequency and Zero-Point Vibrational Energy Scale Factors for Double-Hybrid Density Functionals (and Other Selected Methods): Can Anharmonic Force Fields Be Avoided?, J. Phys. Chem. A 2015, 119, 1701-1714. DOI: 10.1021/jp508422u

${ }^{51}$ Klamt, A. Conductor-like Screening Model for Real Solvents: A New Approach to the Quantitative Calculation of Solvation Phenomena. J. Phys. Chem. 1995, 99, 2224-2235. DOI: 10.1021/j100007a062

${ }^{52}$ Klamt, A. The COSMO and COSMO-RS Solvation Models. Wiley Interdiscip. Rev. Comput. Mol. Sci. 2011, 1, 699-709. DOI: $10.1002 /$ wcms.56 